\title{
OS DELINEAMENTOS DE UMA TEORIA GERAL DOS DIREITOS FUNDAMENTAIS NA PERSPECTIVA DA CONSTITUIÇÃO FEDERAL DE 1988
}

\section{THE OUTLINE OF A GENERAL THEORY OF FUNDAMENTAL RIGHTS IN THE PERSPECTIVE OF THE FEDERAL CONSTITUTION OF 1988}

Juliana Giovanetti Pereira da Silva Mestre em Direitos e Garantias Fundamentais pela UNIMEP. Pós-graduanda em Direito e Processo do Trabalho pela Escola Paulista de Direito. Professora de Direitos Humanos em cursos preparatórios para concurso público. Advogada.

Lais Giovanetti Mestranda em Direitos e Garantias Fundamentais pela UNIMEP. Pós-graduanda em Direito e Processo do Trabalho pela Escola Paulista de Direito. Advogada.

SUBMISSÃO EM 09.05.2016

APROVAÇÃo EM 04.10.2016

DOI: http://dx.doi.org/10.21671/rdufms.v2i1.1739

\begin{abstract}
Resumo: 0 presente artigo tem como objetivo analisar a teoria geral dos direitos fundamentais na perspectiva da Constituição Federal de 1988. Primeiramente, faz-se uma pequena abordagem no que tange a problemática da terminologia, se direitos fundamentais ou humanos, suas conceituações, distinções e a busca de um consenso. Após, passa-se a analisar a evolução histórica dos direitos fundamentais da pré-história à contemporaneidade. Em seguida, verificam-se as principais características de tais direitos. Analisam-se ainda as dimensões ou gerações dos direitos fundamentais e as discussões acerca da expressão mais adequada, se gerações ou dimensões de direitos. Trata também da fundamentalidade formal e material e da classificação dos direitos fundamentais. Por último, faz-se uma abordagem dos direitos fundamentais na Constituição Federal de 1988, demostrando que com o passar dos anos ocorreu uma interpretação ampliativa do texto previsto no caput do artigo 5o da Constituição Federal. Do ponto de vista metodológico, aplicou-se o método da revisão bibliográfica, utilizando-se de deduções para a obtenção da conclusão.
\end{abstract}

Palavras-Chave: Direitos Fundamentais; Conceito; Classificação. 
Abstract: This article aims to analyze the general theory of fundamental rights in the light of the Constitution of 1988. First, a small approach is made regarding the issue of terminology, whether fundamental or human rights, its concepts, distinctions and search a consensus. It passes to analyze the historical evolution of the fundamental rights of prehistory to contemporary. Then, it appears the main characteristics of such rights. It also analyzes dimensions or generations of fundamental rights and the discussions about the most appropriate expression, if generations or dimensions of rights. It also deals with formal fundamentality and material and the classification of fundamental rights. Finally, it makes an approach of fundamental rights in the Constitution of 1988, showing that over the years there has been an ampliative interpretation of the text referred to in the caput of Article 5 of the Federal Constitution. From a methodological point of view, it applied the method of literature review, using deductions to obtain the conclusion.

Keywords: Fundamental rights; Concept; Classification.

SUMÁRIO: 1. Introdução. 2. 0 problema terminológico: direitos fundamentais ou direitos humanos?. 3. A evolução histórica dos direitos fundamentais. 4. As principais características dos direitos fundamentais. 5. As dimensões/gerações dos direitos fundamentais. 6. Da fundamentalidade formal e material dos direitos fundamentais. 7. A classificação dos direitos fundamentais. 8. Os direitos fundamentais na Constituição Federal de 1988. Conclusão. Referências.

\section{INTRODUÇÃo}

O presente estudo volta-se para a construção de uma teoria geral dos Direitos Fundamentais frente à Constituição Federal de 1988. Nesse contexto, o artigo abordará o conceito e a terminologia adequada, vez que apesar de se pronunciar e utilizar o termo Direitos Fundamentais, denota-se que alguns doutrinadores adotam diversas outras expressões como sinônimos, por exemplo, direitos humanos, direitos humanos fundamentais, liberdades públicas, direitos dos cidadãos, direitos da pessoa humana, direitos do Homem. Nesse sentido, o presente trabalho pretende demonstrar qual a melhor terminologia que define o seu conceito técnico jurídico.

Neste ínterim, será tratada a evolução histórica dos Direitos Fundamentais, desde a pré-história até a contemporaneidade. Ressalte-se que os direitos fundamentais ganharam grande importância e relevância no século XX. No ordenamento jurídico interno, tal importância se deu principalmente com o advento da Constituição Federal de 1988 que tratou dos direitos e garantias fundamentais em cinco capítulos específicos, nos artigos 5o a 17, com o devido status jurídico que lhes é pertinente.

Tais direitos foram organizados em direitos e garantias individuais (Capítulo I), direitos sociais (Capítulo II), direitos de nacionalidade (Capítulo III), direitos políticos (Capítulo IV) e direitos que se referem à participação em partidos políticos, bem como a sua existência e organização (Capítulo V), os quais serão analisados em tópico específico. 
Desta forma, a Constituição de 1988 tem se mostrado um grande instrumento de fortalecimento do Estado Democrático de Direito na medida em que atribui aos direitos fundamentais aplicabilidade direta e força vinculante em relação a todos os poderes da República, além da presença de cláusulas pétreas, do controle de constitucionalidade e das garantias processuais que protegem os direitos fundamentais contra a ingerência do Poder Estatal.

Este artigo pretende, portanto, analisar objetivamente a teoria geral dos direitos fundamentais para a compreensão de sua aplicabilidade, suas principais características, classificações e particularidades.

\section{0 Problema Terminológico: DiREITOS FUndaMENTAIS OU DiREITOS HuMANOS?}

Insta esclarecer, antes de adentrar ao problema terminológico que se pretende analisar, que tanto na doutrina quanto no direito positivo - constitucional e internacional -, não há um consenso quanto à utilização das expressões direitos fundamentais e direitos humanos. A doutrina já tem alertado para essa heterogeneidade, ambiguidade e ausência de um consenso na esfera conceitual e terminológica.

Importa ressaltar que além das expressões "direitos fundamentais" e "direitos humanos" que são largamente utilizadas, outras expressões, tais como "direitos do homem", "direitos subjetivos públicos", "liberdades públicas", "direitos individuais", "liberdades fundamentais", são aplicadas quando para designar direitos e garantias referentes ao Homem.

Por sua vez, verifica-se que em virtude da aplicação indiscriminada dos vocábulos direitos humanos ou direitos fundamentais há uma aparente confusão entre os dois termos. No entanto, essa confusão é aceita pela doutrina e pelo direito positivo, principalmente quando compreendidos e quando designam o mesmo conceito e conteúdo.

Frisa-se que essa confusão somente é permitida já que não restam dúvidas que os direitos fundamentais, de certa forma, são também sempre direitos humanos, no sentido que seu titular sempre será o ser humano, ainda que representado por entes coletivos - grupos, povos, nações, Estado (SARLET, 2014, p. 29).

Contudo, apesar de ambos os termos serem aplicados como sinônimos, há distinções entre eles, no que se refere à positivação, perspectiva e efetividade-aplicabilidade.

Para Ingo W. Sarlet, a expressão Direitos fundamentais se aplica para aqueles direitos do ser humano reconhecidos e positivados na esfera do direito constitucional positivo de determinado Estado. Ao passo que a expressão "direitos humanos" 
guardaria relação com os documentos de direito internacional, por referir-se àquelas posições jurídicas que se reconhecem ao ser humano, como tal, independentemente de sua vinculação com determinada ordem constitucional, e que, portanto, aspiram à validade universal, para todos os povos e tempos, de tal sorte que revelam um inequívoco caráter supranacional (internacional) (SARLET, 2014, p. 29).

Outro ponto de distinção para o autor Ingo Wolfgang Sarlet é quanto à eficácia jurídica e social dos direitos humanos que não integram o rol dos direitos fundamentais de determinado Estado. Pois, para alcançar a eficácia depende, em regra, da sua recepção na ordem jurídica interna e, além disso, do status jurídico que esta lhes atribui, visto que do contrário lhes falta o caráter cogente. Assim, a efetivação dos diretos humanos encontra-se, ainda e principalmente, na dependência da boa vontade e da cooperação dos Estados individualmente considerados (SARLET, 2014, p. 34).

Ainda, no âmbito da discussão em torno da melhor terminologia a ser adotada, é relevante destacar que para designar direitos humanos ou direitos fundamentais, alguns autores, mais recentemente, utilizam a expressão "direitos humanos fundamentais" (SARLET, 2014, p. 33).

A discussão quanto ao problema terminológico é longa e não seria possível abordá-la por completo, assim, diante do exposto, o que se pode concluir é que independentemente da ausência de um consenso, o que importa é que o sentido das expressões "direitos humanos" e "direitos fundamentais" não se cuidam de termos reciprocamente excludentes ou incompatíveis, mas sim, de dimensões íntimas e cada vez mais inter-relacionadas, o que não afasta a circunstância de se cuidar de expressões reportadas a esferas distintas de positivação, cujas consequências práticas não podem ser desconsideradas, mas que ao final procuram tratar e proteger os direitos do Homem e a dignidade humana.

\section{A Evolução Histórica dos Direitos Fundamentais}

Os direitos fundamentais são fruto de grande evolução histórica e social ao longo do tempo, eles não surgiram todos de uma vez, mas foram sendo descobertos, declarados conforme as próprias transformações da civilização humana, sendo a luta pela limitação do poder político um dos principais fatores para o acolhimento destes direitos (COMPARATO, 2003, p. 40).

Já na Idade Média, a sociedade deparou-se com a necessidade de proteção de alguns direitos inerentes ao ser humano, compreendendo que sem a proteção destes direitos, jamais haveria uma sociedade justa que pudesse perdurar ao longo dos anos. 
Nas civilizações gregas e romanas já se via bases para o reconhecimento dos direitos humanos, quando se colocavam a pessoa humana como centro da questão filosófica, através de uma explicação antropocentrista sobre a vida humana (MARTINS, 2003, p. 21). A possibilidade de participação do povo nos assuntos da cidade serviu de limitação para o exercício do poder político e os direitos à proteção do homem ganhavam destaque e espaço (СОMРARATO, 2003, p. 43).

Neste período da história também, começou a surgir a ideia de um direito natural ao direito positivo, pela distinção entre lei particular, sendo aquela que cada povo da a si mesmo, e lei comum, que consiste na possibilidade de distinguir entre o que é justo e o que é injusto pela própria natureza humana. Essa distinção feita por Aristóteles tem como exemplo a peça Antígona onde se invoca leis imutáveis contra a lei particular que impedia o enterro de seu irmão (LAFER, 1998, p. 35).

Ainda, foi durante a Idade Média que se difundiram os primeiros documentos escritos reconhecendo direitos a determinados estamentos, a determinadas comunidades, nunca a todas as pessoas, principalmente através de forais ou cartas de franquia (FERREIRA FILHO, 2003, p. 11). Dentre estes documentos, merece destaque a Magna Carta, outorgada por João Sem-Terra no século XII devido a pressões exercidas pelos barões decorrentes do aumento de exações fiscais para financiar campanhas bélicas e pressões da igreja para o Rei submeter-se à autoridade papal (COMPARATO, 2003, p. 71-72).

Na Inglaterra outros documentos foram de fundamental importância como o Petition of Rights, de 1628, que reclama a necessidade de consentimento na tributação, o julgamento pelos pares para a privação da liberdade e a proibição de detenções arbitrárias (FERREIRA FILHO, 2003, p. 12). Também a Lei de habeas corpus, de 1679, que protegia a liberdade de locomoção e que inspirou ordenamentos do mundo todo (COMPARATO, 2003, p. 86).

E no campo teórico na Idade Média foram de fundamental importância os escritos de São Tomás de Aquino ressaltando a dignidade e igualdade do ser humano por ter sido criado a imagem e semelhança de Deus e distinguindo quatro classes de lei, a lei eterna, a lei natural, a lei divina e a lei humana, esta última, fruto da vontade do soberano, entretanto devendo estar de acordo com a razão e limitada pela vontade de Deus (MAGALHÃES, 2000, p. 18-19).

Com a Idade Moderna e o nascimento do Estado Moderno aliado à nova classe burguesa, que necessitava, em sua origem, de um poder absoluto, único, para poder desenvolver sua atividade com segurança, pouco a pouco foi se eliminando a sociedade estamental, para uma nova sociedade onde o indivíduo começava a ter preferência sobre o grupo. 
Embora tenha existido grande avanço durante a Idade Moderna, não se pode falar ainda em direitos considerados universais, ou seja, comuns a toda e qualquer pessoa apenas por pertencer a raça humana, pois os direitos eram meras concessões reais podendo ser revogadas, ou seja, não constituíam um limite permanente na atuação do poder político.

Este período da história da humanidade foi marcado por grandes revoluções que implicaram sobremaneira no desenvolvimento dos direitos humanos. Não se pode negar a importância das Revoluções inglesa, americana e francesa para o reconhecimento de direitos inerentes à pessoa humana, cada uma é claro contribuindo da sua maneira, sendo as duas; últimas as que influenciaram as constituições do século XIX (RUBIO, 1998, p. 82).

Em 1689, o Bill of Rights reconheceu alguns direitos ao indivíduo: o direito de liberdade, o direito a segurança e o direito à propriedade privada, direitos estes que já haviam sido consagrados em outros documentos, entretanto como eram constantemente violados pelo poder real foram recordados na esperança de que desta vez fossem respeitados (ARAGÃO, 2001, p. 32).

Também impôs limites ao poder real, pois deslocou para o Parlamento as competências de legislar e de criar tributos, e institucionalizou a separação de poderes, eliminando o Absolutismo pela primeira vez desde o Início da Idade Moderna, sendo esta sua principal contribuição (COMPARATO, 2003, p. 90).

Em 1776, é elaborada a Declaração de Direitos do Bom Povo da Virgínia afirmando que todos os seres humanos são livres e independentes, possuindo direitos inatos, tais como a vida, a liberdade, a propriedade, a felicidade e a segurança, registrando o início do nascimento dos direitos humanos na história (COMPARATO, 2003, p. 49).

Mas foi em 26 de agosto de 1789 que surge a mais importante e famosa declaração de direitos fundamentais, a Declaração dos Direitos do Homem e do Cidadão, a qual foi marcada pela universalidade dos direitos consagrados, e que (SIQUEIRA, PIRICILLO, 2009) “[...] afirma solenemente que qualquer sociedade em que não esteja assegurada a garantia dos direitos fundamentais nem estabelecida a separação dos poderes não tem constituição” (Artigo 16).

Embora existam diferenças, tanto a Declaração Francesa quanto as americanas e com menos intensidade o Bill of Rights inglês contribuíram com o surgimento do Estado de Direito e com a constitucionalização dos direitos inerentes à pessoa humana.

Nesta esteira, podemos destacar a importância da Declaração Universal dos Direitos do Homem, datada de 10 de dezembro de 1948, quando aprovada pela Assembleia Geral das Nações Unidas em Paris. Neste momento destacou-se a internacionalização dos direitos humanos, fixando-se agora em um contexto in- 
ternacional os direitos fundamentais, o que naturalmente ensejaria uma maior prevalência destes no contexto do ordenamento jurídico interno.

A partir daí os direitos fundamentais passaram a ganhar relevo, tanto na esfera internacional, quanto no ordenamento jurídico interno de cada Estado, passando-se a enxergar os direitos fundamentais sob outra ótica, uma ótica da necessidade, a isonomia passou a estar presente sempre ladeando os direitos fundamentais, sua previsão sempre buscando a limitação do poder estatal, para que pudesse prevalecer a liberdade individual.

\section{As Principais Características dos Direitos Fundamentais}

De acordo com o Juiz de Direito do Tribunal de Justiça do Rio de Janeiro, Alexandre Guimarães Gavião Pinto, e o professor João Trindade Cavalcante Filho, os direitos fundamentais possuem algumas características que serão abordadas e analisadas (PINTO, 2010).

Primeiramente a imprescritibilidade, a qual determina que tais direitos fundamentais não perecem pelo decurso do prazo, pela falta de uso. Mas esta característica não se trata de uma regra geral e absoluta, pois alguns direitos são prescritíveis, como é o caso da propriedade, que pode ser perdida pelo instituto da usucapião.

Outra característica é a inalienabilidade. No tocante à inalienabilidade, ela define que os direitos fundamentais não podem ser transferidos, não podem ser vendidos, nem doados, nem emprestados a outro titular ou titulares de direitos.

A terceira característica é a irrenunciabilidade. Por ela os direitos fundamentais não podem ser renunciados pelo seu titular. Não se pode fazer com eles o que bem se quer, pois eles possuem eficácia objetiva, isto é, importam não apenas ao próprio titular, mas também possuem interesses de toda a coletividade. Também aqui há exceções, pois existem alguns direitos fundamentais que são disponíveis, tais como a intimidade e a privacidade.

Os direitos fundamentais são universais porque abrangem e se aplicam a todos os indivíduos, independentemente de sua nacionalidade, sexo, raça, credo ou convicção político-filosófica.

Eles são também efetivos, uma vez que impõe ao Poder Público, em sua rotineira atuação, a adoção de mecanismos que garantam a efetivação dos relevantes direitos que informam.

São relativos, ou seja, nenhum direito fundamental é absoluto, eis que podem ser relativizados. Primeiramente, porque podem entrar em conflito entre 
si - e, nesse caso, não se pode estabelecer a priori qual direito vai "ganhar" o conflito, pois essa questão só pode ser analisada tendo em vista o caso concreto. E, em segundo lugar, nenhum direito fundamental pode ser usado para a prática de ilícitos. Então - repita-se - nenhum direito fundamental é absoluto.

A indivisibilidade. Os direitos fundamentais são um conjunto, não podem ser analisados de maneira separada, isolada. Assim, desrespeitar a um direito fundamental, na verdade, significa o desrespeito a todos.

E por fim, a última característica apresentada é a aplicabilidade imediata,

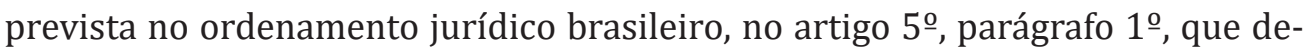
termina que as normas definidoras de direitos e garantias fundamentais têm aplicação imediata. Logo, cabe aos poderes públicos, Judiciário, Legislativo e Executivo desenvolver e garantir a todos estes direitos.

\section{As Dimensões/Gerações dos Direitos Fundamentais}

Os direitos fundamentais desde o seu reconhecimento nas primeiras Constituições passaram por diversas transformações, houve autênticas mutações históricas, quanto ao seu conteúdo, titularidade, eficácia e efetividade.

Nesse sentido, a classificação dos direitos fundamentais em dimensões ou gerações trata-se de uma classificação que leva em conta a cronologia em que os direitos foram paulatinamente conquistados pela humanidade e a natureza de que se revestem (CAVALCANTI FILHO, 2013).

Acrescenta-se que com relação à expressão "gerações" há diversas críticas por parte da doutrina nacional e internacional. Ela pode ensejar a falsa impressão da substituição gradativa de uma geração por outra razão pela qual há quem prefira o termo "dimensões" dos direitos fundamentais. A impropriedade do nome "gerações" em face da continuidade da história dos direitos fez cogitar de outras determinações. Fala-se em "dimensões" ou "configurações" em vez de "gerações". Não há recusa pelos autores do termo "gerações". Mas procura-se aliar o critério histórico a um critério lógico, somar a historicidade com a tipicidade. Apoia-se à sucessão histórica numa tipificação lógica, que revela o perfil dos direitos nos momentos mais expressivos de sua historicidade (SARLET, 2014, p. 45).

Sendo assim, apesar do dissídio terminológico, verifica-se a convergência de autores na utilização da expressão "dimensões" dado ao fato de que os direitos fundamentais desde que reconhecidos nas primeiras Constituições se encontram em constante processo de transformação, culminando com a recepção nos catálogos constitucionais e documentos de Direito Internacional. 
Desta forma, o termo "dimensões", a teoria dimensional, não aponta somente para o caráter cumulativo e para a natureza complementar dos direitos fundamentais, mas afirma sua unidade e indivisibilidade no contexto interno (constitucional) e internacional.

Didaticamente, podemos dizer que os direitos fundamentais de primeira, segunda e terceira "dimensões" formam o lema da Revolução Francesa, a saber: liberdade, igualdade e fraternidade (PINTO, 2010).

Os direitos de primeira geração ou dimensão - individuais ou negativos - foram os primeiros a ser conquistados pela humanidade e se relacionam à luta pela liberdade e segurança diante do Estado. Por isso, caracterizam-se por conterem uma proibição ao Estado de abuso do poder. Trata-se de impor ao Estado obrigações de não fazer. São direitos relacionados às pessoas, individualmente. Exemplo: propriedade, igualdade formal - perante a lei -, liberdade de crença, de manifestação de pensamento, direito à vida, dentre outros (CAVALCANTI FILHO, 2013).

Os direitos de segunda geração ou dimensão - sociais, econômicos e culturais ou direitos positivos - são entendidos como os direitos de grupos sociais menos favorecidos, e que impõem ao Estado uma obrigação de fazer, de prestar - direitos positivos, como saúde, educação, moradia, segurança pública, alimentação. Baseiam-se na noção de igualdade material - redução de desigualdades -, no pressuposto de que não adianta possuir liberdade sem as condições mínimas - educação, saúde - para exercê-la. Nesse caso, em vez de se negar ao Estado uma atuação, exige-se dele que preste saúde, educação etc. Trata-se, portanto, de direitos positivos - impõem ao Estado uma obrigação de fazer. Exemplo: saúde, educação, previdência social, lazer, segurança pública, moradia, direitos dos trabalhadores (CAVALCANTI FILHO, 2013).

Os direitos de terceira geração ou dimensão - difusos e coletivos - são direitos transindividuais, isto é, direitos que são de várias pessoas, mas não pertencem a ninguém isoladamente. Transcendem o indivíduo isoladamente considerado. São também conhecidos como direitos metaindividuais - estão além do indivíduo - ou supraindividuais - estão acima do indivíduo isoladamente considerado. Exemplo de direitos de terceira geração: direito ao meio ambiente ecologicamente equilibrado, direito à paz, ao desenvolvimento, direitos dos consumidores.

Alguns autores defendem a ideia de existência de direitos de quarta geração ou dimensão, mas ainda não há consenso na doutrina sobre qual o conteúdo desse tipo de direitos. Há quem diga tratarem-se dos direitos de engenharia genética - é a posição de Norberto Bobbio -, enquanto outros referem-nos à luta pela participação democrática - corrente defendida por Paulo Bonavides. Por isso mesmo, é discutível a importância dessa categoria (CAVALCANTI FILHO, 2013). 
Diante das críticas levantadas e a despeito de todos os demais aspectos ponderados diante dessa classificação dos direitos fundamentais, crê-se que o mais importante é a postura ativa e responsável que todos, governantes e governados, no que concerne à afirmação e efetivação dos direitos fundamentais de todas as dimensões, pois somente assim estar-se-á no caminho da afirmação de um direito constitucionalmente "altruísta" e "fraterno".

\section{DA Fundamentalidade Formal E MATERial DOS DIREITOS FUNDAMENTAIS}

Para o jusfilósofo Robert Alexy, intrínseca à noção de direitos fundamentais está justamente a característica da fundamentalidade, que de acordo com a sua lição "aponta para a especial dignidade e proteção dos direitos num sentido formal e num sentido material" (SARLET, 2014, p. 75).

A fundamentalidade formal encontra-se ligada ao direito constitucional positivo e resulta dos seguintes aspectos, devidamente adaptados ao nosso direito constitucional pátrio: a) como parte integrante da Constituição escrita, os direitos fundamentais situam-se no ápice de todo o ordenamento jurídico, de tal sorte que - neste sentido - se cuida de direitos de natureza supralegal, b) na qualidade de normas constitucionais, encontram-se submetidos aos limites formais - procedimento agravado - e materiais - cláusulas pétreas dispostas artigo 60 da Constituição Federal, c) por derradeiro, cuida-se de normas diretamente aplicáveis e que vinculam de forma imediata as entidades públicas e privadas - artigo 5oㅗ,$\S 1^{\text {o }}$ da Carta da República (SARLET, 2014, p. 75).

A fundamentalidade material, por sua vez, decorre da circunstância de serem os direitos fundamentais elemento constitutivo da Constituição material, contendo decisões fundamentais sobre a estrutura básica do Estado e da sociedade (SARLET, 2014, p. 75-76).

No tocante a fundamentalidade formal, por exemplo, o Título II da Constituição Federal traz um extenso rol de normas jurídicas definidoras de direitos e garantias fundamentais de forma expressa, esses direitos previstos nesse catálogo são identificados como direitos fundamentais formais.

Outrossim, podem ainda os direitos fundamentais formais serem também materialmente fundamentais. Esses são direitos fundamentais que com relação à organização normativa no texto constitucional, ou estão dispersos em outros artigos da Constituição Federal, a dispersão caracteriza opção técnico-legislativa do constituinte brasileiro - exemplos são os artigos 6ํ e 7ํ da Carta da República -, ou estão fora da Constituição Federal. 
Para o autor Jorge Miranda, “os direitos fundamentais formais são as posições jurídicas subjetivas protegidas pela Constituição Formal por estarem nela inscritas" (MIRANDA, 2000, p. 9).

Desta forma, a formalidade decorre do simples fato de alguns direitos terem sido eleitos pelo Poder Constituinte Originário como direitos fundamentais e consequentemente escritos na Constituição, passando esses direitos a assumir um status jurídico especial, com um regime jurídico próprio.

Konrad Hesse define os direitos fundamentais formais como "aqueles direitos que o direito vigente qualifica de direitos fundamentais" (HESSE, 1998, p. 225).

Na Constituição Federal de 1988 é possível encontrar inúmeros direitos e garantias que pelo seu conteúdo não seriam direitos fundamentais, mas que por vontade do Poder Constituinte Originário, e mesmo do Derivado, se tornaram fundamentais quando ingressaram no texto constitucional.

Contudo, os direitos fundamentais não se esgotam nos indicados pela Constituição, uma vez que ela própria aponta a existência de outros direitos fundamentais nela não positivados, restando insuficiente o conceito formal de direitos fundamentais.

Já a fundamentalidade material dos direitos fundamentais decorre da abertura da Constituição a outros direitos fundamentais não expressamente constitucionalizados, direitos fundamentais que estão fora da Constituição formal, conforme exposto no art. $5^{\circ}, \S^{\circ} 2^{\circ}$ da CF.

Tem-se, assim, que a Constituição Federal possui um elenco aberto de direitos e garantias, que não estão restritos ao Título II, bem como não se encontram limitados ao texto Constitucional. Resta ao intérprete a tarefa de localizar estes direitos e garantias não expressos no texto constitucional.

Assim, pode-se classificar os direitos fundamentais segundo a fundamentalidade em: a) direitos constitucionais formais não-fundamentais, são direitos formalmente constitucionais, estão dentro da constituição formal, mas não traduzem direitos fundamentais; b) direitos constitucionais formalmente fundamentais, são aqueles direitos constitucionais que foram definidos pelo Poder Constituinte Originário ou Derivado no texto constitucional como sendo direitos fundamentais, encontram-se no rol dos direitos fundamentais; c) direitos constitucionais formalmente e materialmente fundamentais, são aqueles direitos constitucionais que foram definidos pelo Poder Constituinte Originário ou Derivado no texto constitucional como sendo direitos fundamentais e que possuem um conteúdo essencial fundamental, que estão previstos ou no Título II da CF ou dispersos em outros artigos pelo texto 
constitucional; d) direitos constitucionais materialmente fundamentais, são aqueles direitos constitucionais que não foram definidos pelo Poder Constituinte Originário ou Derivado no texto constitucional como sendo direitos fundamentais apesar de possuírem um conteúdo essencial fundamental; e) direitos materialmente fundamentais fora do catálogo constitucional, como por exemplo os constantes na legislação ordinária ou de tratados internacionais que tenham conteúdo normativo fundamental e que por força do art. 50 $\S 2^{\circ}$ gozaram do mesmo regime jurídico dos direitos fundamentais, como por exemplo os direitos de personalidade constantes na legislação civil.

Os direitos fundamentais, sejam formais ou materiais, gozam de aplicabi-

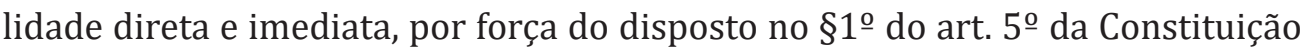
Federal, bem como vinculam imediatamente os poderes públicos.

\section{A Classificação dos Direitos Fundamentais}

À luz do direito constitucional positivo brasileiro, a questão da classificação dos direitos fundamentais revela-se como sendo particularmente problemática.

O problema classificatório reside da diversidade de funções exercidas pelos direitos fundamentais, de sua distinta e complexa estrutura normativa, bem como das especificidades de cada ordem constitucional. Há, também, diversos critérios classificatórios utilizados pelas doutrinas que nem sempre são compatíveis entre si, além de muitas vezes não ser compatíveis com o direito constitucional positivo.

Uma classificação que se revela viável pelo que já foi exposto é a que distingue os "direitos fundamentais em ESCRITOS ou EXPRESSAMENTE POSITIVADOS - na Constituição ou em tratados internacionais -, e os NÃO ESCRITOS - implícitos ou decorrentes do regime e dos princípios -" (SARLET, 2014, p. 167), critérios esses que se baseiam pela fundamentalidade dos direitos fundamentais - material e formal -, na problemática da abertura do catálogo, mais especificamente, no disposto no artigo 5ํㅜㄹ parágrafo $2^{\circ}$ da Constituição Federal.

Para o doutrinador Ingo W. Sarlet é na teoria de George Jellinek juntamente com a do ilustre Robert Alexy que se encontram as formas classificatórias mais relevantes e férteis, cientificamente resistentes, além de constitucionalmente adequadas (SARLET, 2014, p. 168).

George Jellinek formulou a teoria da multifuncionalidade dos direitos fundamentais, de acordo com a qual o indivíduo, como vinculado a determinado Estado, encontra sua posição relativamente a este vinculado por quatro espécies e situações jurídicas (status), seja como sujeito de deveres, seja como titular de direitos (SARLET, 2014, p. 162). 
De acordo com a lição de Jellinek, na formulação que lhe deu Alexy, o status seria uma espécie de estado - uma situação - no qual se encontra o indivíduo o qual qualificaria sua relação com o Estado.

O primeiro status é o passivo - status subjectionis -, no qual o indivíduo estaria subordinado aos poderes estatais, sendo meramente detentor de deveres, e não de direitos, significando de outra banda, que o Estado possui a competência de vincular o cidadão juridicamente por meio de mandamentos e proibições. Para além desse status subjectionis, Jellinek toma como base a ideia de que, por ser dotado de personalidade, ao indivíduo é reconhecido um status negativus, consistente numa esfera individual de liberdade imune ao jus imperi do Estado, que, na verdade, é poder juridicamente limitado. 0 terceiro status referido por Jellinek - e que complementaria o staus negativus - é o assim denominado status positivus - ou status civitatis -, no qual ao indivíduo seria assegurada juridicamente a possibilidade de utilizar-se das instituições estatais e de exigir do Estado determinadas ações positivas. É no status positivus que se poderia, grosso modo, enquadrar os assim denominados direitos a prestações estatais, incluindo os direitos sociais (SARLET, 2014, p. 162).

Jellinek complementa sua teoria com o reconhecimento de um status activus ao cidadão, no qual este passa a ser considerado titular de competências que lhe garantem a possibilidade de participar ativamente da formação da vontade estatal, como, por exemplo, pelo direito de voto (SARLET, 2014, p. 162).

Analisando a teoria exposta, registra-se a convergência, no que concerne à divisão, dos direitos fundamentais em dois grandes grupos, direitos fundamentais como DIREITOS DE DEFESA e pelos DIREITOS A PRESTAÇÕES (SARLET, 2014, p. 168).

Para o Prof. Canotilho há também outras divisões, desta forma os direitos a prestações podem ser classificados em direitos ao acesso e utilização de prestações estaduais - por sua vez subdivididos em direitos derivados e direitos originários a prestações - e, por outro lado, em direitos à participação na organização e procedimento (SARLET, 2014, p. 168-169).

Já para o jusfilósofo Alexy, os direitos a prestações abrangem os direitos prestacionais em sentido amplo - direitos a proteção e direitos à organização e ao procedimento -, bem como os direitos a prestações stricto sensu, que se identifica com os direitos sociais de natureza positiva (SARLET, 2014, p. 168-169).

Importante lembrar que estas classificações não traduzem uma dicotomia ou dualismo. Sempre é preciso distinguir o direito fundamental como um todo, ou sem sentido amplo, que compreende sempre ambas as facetas (negativa e positiva).

Reitera-se, por fim, que tais teorias não infirmam o regime jurídico unificado e a interdependência de todos os direitos fundamentais, mas apenas parte da 
distinção entre o objeto próprio de cada situação - ou posição - jurídica subjetiva na qual se compõe os direitos fundamentais (SARLET, 2014, p. 174).

\section{OS Direitos Fundamentais NA ConstituiçÃo FEDERAL DE 1988}

Os direitos fundamentais foram inseridos de maneira explícita nas constituições há pouco tempo, mais precisamente após a 2ª Grande Guerra Mundial, quando os povos começaram a se preocupar com a proteção aos direitos da pessoa humana, em virtude das violências cometidas pelos regimes fascista, stalinista e nazista, como também pelo perigo de ameaça à tranquilidade universal decorrente da instabilidade das relações entre os diversos países.

Sobre o assunto, o professor José Afonso da Silva aponta que o reconhecimento dos direitos fundamentais do homem em enunciados explícitos nas declarações de direitos é recentee está longe de se esgotarem suas possibilidades, já que a cada passo na etapa da evolução da Humanidade importa na conquista de novos direitos. Mais que conquista, o reconhecimento desses direitos caracteriza-se como reconquista de algo que, em termos primitivos, se perdeu, quando a sociedade se dividira em proprietários e não proprietários (SARLET, 2000, p. 153).

No Brasil, também houve reflexos dessa preocupação com os direitos fundamentais dos seres humanos, e em 1985 iniciou-se um processo de redemocratização no país, após um regime ditatorial iniciado com o golpe de 1964 que desembocou na promulgação da Constituição Federal de 1988, a qual não apenas estabelece um regime político democrático, como propicia um grande avanço no que se refere aos direitos e garantias fundamentais.

Foi na Constituição Federal de 1988 que a matéria dos direitos fundamentais foi tratada com o status jurídico que lhes é devido, pela primeira vez na história do constitucionalismo pátrio.

Esse tratamento e preocupação foi fruto de uma reação do Constituinte, das forças sociais e políticas ao regime de restrição e aniquilação das liberdades fundamentais do período ditatorial.

Destarte, os direitos fundamentais na Lei Maior brasileira vigente se tornaram os mais abrangentes e extensos de todas as Constituições até então vigorantes no país.

Ressalta-se que além das liberdades públicas, a Constituição de 1988 assegura a igualdade de todos perante a lei e a dignidade da pessoa humana.

A Constituição Federal de 1988, no tocante à temática dos direitos fundamentais, inovou com o mandado de segurança coletivo, o habeas data para assegurar o conhecimento de informações relativas à sua pessoa e o mandado de injunção para 
exigir o cumprimento da Constituição. A Carta Maior assegura a inviolabilidade de cinco direitos fundamentais: a) direito à vida; b) direito à liberdade; c) direito à igualdade; d) direito à segurança; e) direito à propriedade, entre outros.

A Carta Magna acolhe além dos direitos explícitos os chamados direitos implícitos contidos em outros artigos além do artigo 5ํㅜ, como os direitos fundamentais sociais previstos nos artigos 6ํㅜ e 7ํ․ Ela admite também a incorporação de outros direitos presentes em tratados internacionais em que a República Federativa seja parte, conforme o artigo 5ํㅜ , parágrafo $2^{\circ}$.

\section{CoNCLUSÃo}

Este artigo buscou evidenciar a presença dos direitos fundamentais no ordenamento jurídico brasileiro.

Em primeiro lugar fez-se uma breve análise sobre a definição dos direitos fundamentais e a problemática envolvida, para, ogo em seguida, demonstrar a diferença entre direitos fundamentais e humanos, o que tem sido enfrentado diariamente pela doutrina constitucionalista.

Em seguida, relatou-se a evolução histórica dos direitos fundamentais, sendo que até o presente momento a doutrina não conseguiu uniformizar o entendimento, sendo que uma corrente entende que surgiu na Inglaterra com a Magna Carta do Rei João Sem Terra e outros, ligados ao entendimento cristão, afirmam que surgiu com a Lei de Deus.

Abordou-se a localização dos direitos fundamentais na nossa Constituição Federal de 1988, concluindo que a maior parte desses direitos se encontra principalmente entre os artigos 5o e 17, não se descartando a hipótese da presença de outros direitos fundamentais em outros artigos da Constituição e fora dela tratados internacionais.

Seguindo esta análise, percebeu-se que os direitos fundamentais não estão limitados à Constituição, e estão nela dispostos apenas para eivarem-se de uma maior intangibilidade. Nesta tangente, verificou-se que os direitos fundamentais não se restringem à esfera interna, mas são um misto de conquistas derivadas da luta pelo direito e da tentativa de regulação da vida em uma sociedade cada vez mais internacional.

Ressaltou-se neste sentido que a disposição dos direitos fundamentais no sistema constitucional brasileiro é o reflexo de diversas correntes doutrinárias desenvolvidas na Alemanha, Estados Unidos e França após a 2ª Guerra Mundial. 
A Constituição de 1988 tem se mostrado um grande instrumento de fortalecimento do Estado Democrático de Direito na medida em que atribui aos direitos fundamentais aplicabilidade direta e força vinculante em relação a todos os poderes da república.

Sendo assim, por todo o exposto, uma conclusão é inevitável de que os direitos fundamentais, que são aqueles considerados indispensáveis à pessoa humana, são mais do que necessários para assegurar a todos uma existência livre, igualitária, justa e digna, por isso, o Estado não deve apenas reconhecê-los formalmente, pois é imperiosa a busca incessante e rotineira de sua plena concretização, incorporando-se à vida dos cidadãos, para se aperfeiçoar o Estado Democrático de Direito.

\section{REFERÊNCIAS}

ARAGÃO, Selmo Regina. Direitos Humanos: do Mundo Antigo ao Brasil de Todos. $3^{\mathbf{a}}$ ed. Rio de Janeiro: Editora Forense, 2001.

BARROSO, Darlan ; ARAUJO JUNIOR, Marco Antonio. Vade Mecum. 2ª ed, São Paulo: RT, 2012. CAVALCANTI FILHO, João Trindade. Teoria geral dos direitos fundamentais. Disponível em: $<$ http://www.stf.jus.br/repositorio/cms/portaltvjustica/portaltvjusticanoticia/anexo/ joao_trindadade_teoria_geral_dos_direitos_fundamentais.pdf>. Acesso em 06 jul. 2015.

COMPARATO, Fábio Konder. A Afirmação Histórica dos Direitos Humanos. 3aㅡ ed. São Paulo: Saraiva, 2003.

FERREIRA FILHO, Manoel Gonçalves. Aspectos do Direito Constitucional Contemporâneo. São Paulo: Saraiva, 2003.

HESSE, Konrad. Elementos de direito constitucional da república Federal da Alemanha. Tradução de Luíz Afonso Heck. Porto Alegre: Sergio Antonio Fabris Editor, 1998.

HUMAN RIGHTS. Artigo 16 da Declaração dos Direitos do Homem e do Cidadão, de 26 de agosto de 1789. Disponível em: <http://www.humanrights.com/pt/what-are-human-rights/universal-declaration-of-human-rights/articles-11-20.html>. Acesso em 06 jul. 2015.

LAFER, Celso. A Reconstrução dos Direitos Humanos: Um diálogo com o pensamento de Hannah Arendt. São Paulo: Companhia das Letras, 1998.

LALAGUNA, Paloma Durán. Manual de Derechos Humanos. Granada: Comares, 1993.

MAGALHÃES, José Luiz Quadros de. Direitos Humanos (sua história, sua garantia e a questão da indivisibilidade). São Paulo: Editora Juarez, 2000.

MARTínEZ, Gregório Peces-Barba. Curso de Derechos Fundamentales: Teoría General. Universidad Carlos III de Mardid. Madrid: Boletín Oficial del Estado, 1999.

MARTINS, Flademir Jerônimo Belinati. Dignidade da Pessoa Humana: Princípio Constitucional Fundamental. Curitiba: Juruá Editora, 2003.

MIRANDA, Jorge. Manual de Direito Constitucional. Tomo IV. 3a ed. Coimbra: Coimbra Editora, 2000.

Revista DIREITO UFMS | Campo Grande, MS | v. 2 | n. 1 | p. 39 - 55 | jul./dez. 2016 
PINTO, Alexandre Guimarães Gavião. Direitos fundamentais - legítimas prerrogativas de liberdade, igualdade e dignidade. Disponível em: <http://www.tjrj.jus.br/c/document_ library/get_file?uuid=ae67daf5-7ca9-408c-93b6-b58186a81197\&groupId=10136>. Acesso em 06 jul.2015.

RUBIO, Valle Labrada. Introduccion a la Teoria de los Derechos Humanos: Fundamento. Historia. Declaracion Universal de 10 de diciembre de 1948. Madrid: Civitas, 1998.

SARLET, Ingo Wolfgang. A Eficácia dos Direitos Fundamentais - Uma teoria geral dos direitos fundamentais na perspectiva constitucional. 12ª ed. Porto Alegre: Livraria do Advogado.

SILVA, José Afonso da. Curso de direito constitucional positivo. 19a ed. São Paulo: Malheiros Editores, 2000.

SIQUEIRA, Dirceu Pereira; PICCIRILLO, Miguel Belinati. Direitos fundamentais: a evolução histórica dos direitos humanos, um longo caminho. Disponível em: <http://www.ambitojuridico.com.br/site/index.php?n_link=revista_artigos_leitura\&artigo_id=5414>. Acesso em 06 jul. 2015. 
